\title{
Faktor-Faktor yang Mempengaruhi Sticky Cost
}

\author{
Zul Azmi ${ }^{1}$, Januryanti ${ }^{2 *}$ \\ ${ }^{1,2}$ Program Studi Akuntansi, Fakultas Ekonomi dan Bisnis, Universitas Muhammadiyah Riau \\ Correspondence email: zulazmi@umri.ac.id
}

\begin{abstract}
Abstrak. Penelitian ini bertujuan untuk menguji faktor-faktor yang mempengaruhi sticky cost. Secara khusus, penelitian ini menguji pengaruh penjualan, ukuran perusahaan, intensitas aset dan modal intelektual terhadap sticky cost pada perusahaan manufaktur sektor industri dan barang konsumsi yang terdaftar di Bursa Efek Indonesia. Data penelitian ini terdiri dari 32 perusahaan pada periode 2012-2017 dengan 192 pengamatan. Data dianalisis dengananalisis regresi berganda. Hasil penelitian ini menunjukkan bahwa variabel penjualan, ukuran perusahaan, intensitas aset, modal intelektual berpengaruh terhadap sticky cost. Penelitian ini mengaris bawahi bahwa perusahaan tidak menurunkan biaya terkait modal intelektual meskipun terjadi penurunan penjualan, melainkan akan berusaha mencari solusi melalui sumberdayanya untuk meningkatkan produktivitas penjualan. Dengan demikian, perusahaan akan membutuhkan biaya lebih oleh karena itu akan menimbulkan adanya sticky cost.
\end{abstract}

Kata Kunci: Sticky Cost; Modal Intelektual; Intensitas Aset

Abstract. This study aims to examine the factors that affect sticky cost. Specifically, this study examines the effect of sales, company size, asset intensity, and intellectual capital on sticky costs in industrial and consumer goods manufacturing companies listed on the Indonesia Stock Exchange. The research data consisted of 32 companies in the 2012-2017 period with 192 observations. Data were analyzed by multiple regression analysis. The results of this study indicate that the variable sales, company size, asset intensity, intellectual capital affect sticky cost. This research underlines that the company does not reduce costs related to intellectual capital despite a decrease in sales, but will try to find solutions through its resources to increase sales productivity. Thus, the company will need more costs because it will cause sticky costs.

Keywords: Sticky Cost; Intelectual Capital; Assets Intensity

\section{Pendahuluan}

Manajer perusahaan harus memahami perilaku biaya dan informasi mengenai akuntansi manajemen lainnya agar dapat mendesain perencanaan estimasi biaya yang lebih akurat dimasa depan dan mengoptimalkan serta meningkatkan efisiensi biaya dalam pengelolaan sumber daya perusahaan. Biaya memiliki hubungan yang simetris dengan volume atau aktifitas perusahaan. Namun, pada pelaksanaannya ditemukan bahwa biaya meningkat lebih tinggi ketika terjadinya peningkatan pendapatan dibandingkan penurunan biaya ketika terjadinya penurunan pendapatan. Perilaku biaya ini dikenal sebagai kelengketan biaya (sticky cost). Sticky cost terjadi karena ketidakpastian permintaan dimasa depan yang menyebabkan manajer menunda melakukan pengurangan biaya sampai mereka yakin terjadinya penurunan aktifitas. Berdasarkan laporan keuangan perusahaan, fenomena sticky cost dapat digambarkan pada beberapa perusahaan pada Tabel.1.

Berdasarkan Tabel 1 menunjukkan perubahan penjualan dan perubahan beban penjualan, administrasi dan umum pada perusahaan AISA dan ROTI yang mengalami ketidakseimbangan. Hampir setiap tahunnya biaya yang dikeluarkan untuk produksi lebih besar dari penjualan yang didapat. Puncaknya pada tahun 2016-2017 kedua perusahaan mengalami penjualan yang minus dan biaya beban penjualan, administrasi, dan umum yang besar. Hal ini yang mengindikasikan adanya sticky cost pada perusahaan. Penjualan merupakan aktifitas utama yang dilakukan perusahaan untuk menjaga keberlangsungan hidup perusahaan. Manajer optimis bahwa penjualan akan mengalami peningkatan di masa depan. Pertimbangan manajer yang memprediksi penjualan akan meningkat pada masa depan akan mendorong manajer cenderung untuk mempertahankan sumber daya yang tidak digunakan dibandingkan mengeluarkan biaya penyesuaian ketika permintaan mengalami penurunan. Harapan dalam hal ini jika kepercayaan manajemen membuahkan hasil akan meningkatkan laba perusahaan dan membuat investor membuat keputusan investasi pada perusahaan (Aprayuda et al., 2021; Aprayuda \& Misra 2020; Putra et al., 2020).

Penelitian Anderson (2003) menunjukkan bahwa terdapat indikasi terjadinya sticky cost pada biaya penjualan administrasi dan umum pada perusahaan di Amerika dimana ketika terjadi kenaikan pendapatan sebesar 1\%, rata-rata biaya akan meningkat sebesar $0,55 \%$ sedangkan apabila terjadi penurunan pendapatan sebesar $1 \%$, rata-rata biaya menurun hanya sebesar $0,35 \%$. 
Tabel 1.

Perusahaan Yang Mengalami Sticky Cost

\begin{tabular}{|c|c|r|r|r|r|}
\hline \multirow{2}{*}{ Kode Perusahaan } & \multirow{2}{*}{ Periode } & \multicolumn{2}{|c|}{ Perubahan Penjualan } & \multicolumn{2}{c|}{ Perubahan Beban Penjualan, Administrasi dan Umum } \\
\cline { 2 - 6 } & & Dalam Jutaan & \multicolumn{2}{c|}{$\%$} & \multicolumn{2}{c|}{ Dalam Jutaan } & $\%$ \\
\hline \multirow{4}{*}{ AISA } & $2012-2013$ & 1.309 .122 & 47.6 & 118.639 & 66.2 \\
\cline { 2 - 7 } & $2013-2014$ & 1.083 .239 & 26.7 & 89.660 & 30.1 \\
\cline { 2 - 7 } & $2014-2015$ & 870.921 & 16.9 & 152.219 & 23.7 \\
\cline { 2 - 7 } & $2016-2017$ & $(1.624 .948)$ & $(24.8)$ & 249.209 & 37.3 \\
\hline \multirow{3}{*}{ ROTI } & $2012-2013$ & 314.694 & 26.4 & 118.147 & 31.9 \\
\cline { 2 - 7 } & $2013-2014$ & 294.240 & 15.6 & 100.322 & 15.7 \\
\cline { 2 - 7 } & $2014-2015$ & 347.419 & 16.0 & 179.003 & 24.2 \\
\cline { 2 - 7 } & $2016-2017$ & $(30,821)$ & $(1.2)$ & 188.838 & 20.6 \\
\hline
\end{tabular}

Sumber: Laporan Laba Rugi Komprehensif 2012-2017

Windyastuti (2013) menunjukkan pada perusahaan manufaktur di Indonesia periode 1999-2011 bahwa kenaikan penjualan bersih sebesar 1 juta Rupiah menyebabkan kenaikan biaya penjualan, administrasi dan umum sebesar 0,016 juta Rupiah tetapi penurunan penjualan bersih sebesar 1 juta Rupiah hanya menyebabkan penurunan biaya penjualan, administrasi dan umum sebesar 0,003 juta Rupiah. Hal ini bertentangan dengan penelitian yang dilakukan oleh Nugroho dan Endarwati (2013) yang menunjukkan bahwa kenaikan penjualan sebesar 87\% diikuti oleh kenaikan biaya operasional sebesar $76 \%$ dan ketika terjadi penurunan penjualan sebesar $13 \%$ biaya operasional menurun sebesar $24 \%$ sehingga disimpulkan bahwa sticky cost tidak terjadi pada perusahaan manufaktur di Indonesia periode 2010-2011. Penelitian yang dilakukan oleh Nelmida dan Siregar (2016) juga menjelaskan bahwa tidak terjadi sticky cost pada perusahaan yang terdaftar di Bursa Efek Indonesia periode 2009-2015 dimana ketika terjadi perubahan penjualan sebesar $1 \%$ menyebabkan perubahan biaya selling, general dan administration sebesar 0,34\% dan ketika terjadi penurunan penjualan sebesar 1\%, biaya selling, general dan administration mengalami perubahan yang lebih besar yaitu $0,56 \%$.

Komponen biaya yang dimiliki oleh setiap perusahaan berbeda-beda. Perusahaan dengan ukuran besar cenderung memiliki komponen biaya yang lebih kompleks dan akses terhadap modal lebih luas. Semakin besar ukuran perusahaan maka kemungkinan untuk terjadinya sticky cost juga akan semakin besar. Sementara itu, perusahaan kecil memiliki akses terhadap modal lebih terbatas daripada perusahaan besar. Terjadinya sticky cost juga dapat dipengaruhi oleh intensitas aset yang dimiliki oleh perusahaan. Indikasi terjadinya sticky cost yaitu ketika terjadi peningkatan penjualan, manajer dihadapkan pada keputusan apakah harus membeli mesin atau peralatan baru untuk memenuhi kebutuhan kenaikan penjualan. Indikasi sticky cost pada intensitas aset ini dilhat lebih ke aset tetap karena aset tetap mengalokasikan biaya tambahan walaupun tidak secara rill dikeluarkan namun dapat mengurangi laba perusahaan. Penelitian mengenai intensitas aset terhadap sticky cost yang dilakukan oleh Afiffah, et al (2018), Wahyuningtyas dan Nugrahanti (2014) menemukan bahwa intensitas aset berpengaruh signifikan terhadap sticky cost. Penelitian dengan hasil yang berbeda dikemukakan oleh Nelmida dan Siregar (2016) bahwa intensitas aset tidak berpengaruh signifikan terhadap sticky cost.

Aset tak berwujud (intangible asset) berupa modal intelektual layak diperhitungkan untuk meningkatkan nilai tambah perusahaan. Modal intelektual terdiri dari atas 3 (tiga) elemen yaitu modal manusia (human capital), modal struktural (structural capital) dan modal pelanggan (customer capital). Modal manusia (human capital) mengacu pada kemampuan sumber daya manusia dalam belajar dan dalam menghasilkan aset berwujud dan tidak berwujud. Penelitian yang dilakukan oleh Mohammadi dan Taherkhani (2017) menunjukkan bahwa modal intelektual berpengaruh negatif terhadap sticky cost dimana peningkatan modal intelektual sebesar 1 unit, sticky cost akan mengalami penurunan sebesar 0,006 unit. Ramashar et al., (2019) menunjukkan bahawa modal intelektual tidak berpengaruh terhadap terjadinya sticky cost. Sementara itu, penelitian yang dilakukan oleh Venieris, et al (2015) mengemukakan bahwa perusahaan dengan modal intelektual yang tinggi menunjukkan terjadinya sticky cost. Tujuan penelitian ini mengidentifikasi faktor-faktor yang mempengaruhi sticky cost. Riset ini dikembangkan berdasarkan penelitian Mohammadi dan Taherkhani (2017).

\section{Tinjauan Pustaka \\ Teori Stakeholder}

Teori stakeholder menyatakan bahwa seluruh stakeholder memiliki hak untuk disediakan informasi tentang bagaimana aktifitas organisasi mempengaruhi mereka (sebagai contoh melalui polusi, sponsorship, inisiatif pengamanan dan lain-lain), bahkan ketika mereka memilih untuk menggunakan informasi tersebut dan bahkan ketika mereka tidak dapat secara langsung memainkan peran yang konstruktif dalam kelangsungan hidup organisasi (Deegan, 2004 dalam Ulum, 2009). Dalam konsep stakeholder theory, hubungan dengan penelitian ini adalah ketika suatu perusahaan dihadapkan pada masalah yang menyangkut biaya atas kegiatan produktivitas perusahaan. Suatu perusahaan dituntut untuk meminimalisir biaya dan mempergunakan sumber daya secara efektif dan efisien guna memaksimalkan keuntungan. Ketika manajer merasa terjadi ketidaksesuaian antara biaya yang dikeluarkan dengan aktivitas perusahaan, maka peran stakeholder atau pihak yang berkepentingan terhadap perusahaan ikut membantu 
dan memberikan masukan terhadap seorang manajer sebagai solusi untuk pengambilan keputusan guna meminimalisir terjadinya sticky cost.

\section{Penjualan terhadap Sticky Cost}

Stickiness pada biaya penjualan, administrasi dan umum terjadi jika manajer memutuskan untuk menahan sumber daya yang tidak terpakai daripada melakukan adjustment cost ketika volume penjualan mengalami penurunan. Manajer ragu untuk mengurangi utilization ketika penjualan menurun karena mengantisipasi jika terjadi kenaikan penjualan kembali. Sehingga biaya penjualan, administrasi dan umum akan tetap tinggi karena tidak segera disesuaikan (Wahyuningtyas dan Nugrahanti, 2014). Hal ini menunjukkan adanya keterkaitan dari teori agensi bahwa manajemen sebagai agen mestinya mementingkan kepentingan prinsipal, akan tetapi tidak tertutup kemungkinan manajemen hanya mementingkan kepentingannya sendiri untuk memaksimalkan utilitas. Ketika manajer percaya bahwa penurunan penjualan adalah sementara, manajer akan memutuskan untuk mempertahankan sumber daya ketika volume penjualan mengalami penurunan, sehingga perusahaan harus menanggung biaya sumber daya yang menganggur. Kemudian, harapannya akan meingkatkan kinerja perusahaan (Husni et al., 2020), dan peningkatan saham untuk menarik investor lewat media informasi (Sofyan et al., 2020). Penelitian Anderson (2003) menunjukkan bahwa terdapat indikasi terjadinya sticky cost pada biaya penjualan administrasi dan umum .Berdasarkan uraian tersebut diatas maka dapat dirumuskan hipotesis penelitian ini adalah sebagai berikut:

H1: Penjualan berpengaruh terhadap sticky cost

\section{Ukuran perusahaan terhadap sticky cost}

Hery (2017) menunjukkan ukuran perusahaan adalah suatu skala untuk mengklasifikasikan besar kecilnya perusahaan menurut berbagai cara antara lain dengan total asset, total penjualan, nilai pasar saham dan sebagainya. Pada dasarnya ukuran perusahaan hanya terbagi dalam 3 kategori yaitu perusahaan besar (large firm), perusahaan menengah (medium-size) dan perusahaan kecil (small firm). Penentuan ukuran perusahaan ini didasarkan kepada total asset perusahaan. Perusahaan berukuran large memiliki komponen biaya yang lebih kompleks daripada perusahaan berukuran medium dan small. Perusahaan berukuran large tentunya memiliki total biaya yang lebih besar dibandingkan perusahaan small dan medium. Sehingga besarnya selling, general and administrative cost pada perusahaan large, medium dan small akan semakin besar ketika ukuran perusahaan semakin besar. Hal ini menunjukkan adanya keterkaitan dari teori stakeholder yang mempengaruhi manajemen untuk dapat berfokus pada fungsi dan tingkat pengendalian atas sumber daya demi mencapai tujuan perusahaan yaitu memperoleh keuntungan melalui penjualan yang meningkat. Pamplona, et al (2016) menemukan indikasi sticky cost pada perusahaan berukuran large di Brazil, Chile dan Meksiko. Berdasarkan uraian tersebut diatas maka dapat dirumuskan hipotesis penelitian ini adalah sebagai berikut:

H2: Ukuran perusahaan berpengaruh terhadap sticky cost

\section{Pengaruh intensitas aset terhadap sticky cost}

Aset merupakan sumber daya yang dikuasai oleh suatu perusahaan dengan tujuan untuk menghasilkan laba (Subramanyam, 2016). Ketika volume penjualan mengalami penurunan, manajer akan berusaha menurunkan skala pembelian pada persediaan bahan baku yang pengadaannya dengan melakukan pembelian dengan pihak luar. Manajer akan lebih mudah untuk mengurangi atau menghentikan bahan baku tersebut. Akan tetapi untuk input yang diperoleh dari dalam perusahaan (aset perusahaan), pelepasan aset ketika terjadi penurunan penjualan sangatlah mahal. Perusahaan harus membayar biaya pembelian aset dan kehilangan investasi perusahaan yang spesifik. Pada saat terjadi penurunan penjualan, perusahaan yang memiliki aset lebih tinggi akan mengalami kelengketan biaya karena mengalami dilema yang lebih besar. Sehingga, semakin tinggi intensitas aset maka kelengketan biaya pada biaya penjulan, administrasi dan umum akan semakin tinggi juga (Afiffah, et al 2018). Penelitian mengenai intensitas aset terhadap sticky cost yang dilakukan oleh Afiffah, et al (2018) menemukan bahwa intensitas aset berpengaruh signifikan terhadap sticky cost. Wahyuningtyas dan Nugrahanti (2014) menemukan bahwa intensitas aset berpengaruh terhadap tingkat sticky cost pada biaya penjualan, administrasi dan umum. Semakin tinggi intensitas aset maka semakin tinggi pula sticky cost. Berdasarkan uraian tersebut maka dapat dirumuskan hipotesis penelitian ini adalah sebagai berikut:

H3: Intensitas aset berpengaruh terhadap sticky cost

\section{Pengaruh modal intelektual terhadap sticky cost}

Perusahaan yang memandang pengembangan aset tak berwujud sebagai sebuah investasi yang berkontribusi jangka panjang, enggan untuk mengurangi investasi ini sebagai tanggapan terhadap penurunan volume penjualan yang mengakibatkan terjadinya sticky cost. Sementara bagi perusahaan yang memandang pengembangan aset tak berwujud sebagai suatu pengeluaran lebih bersemangat untuk mengurangi biaya sebagai respon terhadap penurunan penjualan 
untuk meningkatkan pendapatan yang dilaporkan dan untuk memperlancar volatilitas pendapatan antara periode akuntansi (Venieris, 2015). Penelitian yang dilakukan oleh Mohammadi dan Taherkhani (2017) menganalisis hubungan antara organizational capital, intellectual capital and cost stickiness pada perusahaan yang terdaftar di Tehran Stock Exchange menemukan bahwa modal intelektual berpengaruh signifikan terhadap cost stickiness. Berdasarkan uraian tersebut diatas maka dapat dirumuskan hipotesis penelitian ini adalah sebagai berikut:

H4: Modal intelektual berpengaruh terhadap sticky cost

\section{Metode}

Data pada penelitian ini dimbil dari perusahaan manufaktur sektor barang konsumsi pada periode 2012-2017. Dengan teknik sampel yang digunakan dalam menyeleksinya adalah menggunakan purposive sampling. Hasil akhir menunjukkan sebanyak 48 perusahaan, 11 perusahaan tidak melaporkan tahunannya secara konsisten serta 5 perusahaan mengalami delisting, sehingga hanya 32 perusahaan yang lolos dari purposive sampling.

Sticky cost merupakan suatu keadaaan dimana biaya cenderung melekat atau kaku terhadap perubahan aktifitas. Sticky cost dilihat dari perubahan biaya penjualan, administrasi dan umum dalam periode tertentu dibandingkan dengan periode sebelumnya $\left(\mathrm{t}_{-1}\right)$ yang dihitung dengan rumus sebagai berikut:

Perubahan biaya PAU $(\triangle \mathrm{PAUi}, \mathrm{t})=\frac{\mathrm{PAU} t}{\mathrm{PAU}, \mathrm{t}-1}$

Penjualan merupakan suatu usaha yang dilakukan perusahaan untuk menyalurkan barang yang telah diproduksi kepada pembeli dengan tujuan untuk mendapatkan laba. Nilai penjualan diukur dengan total penjualan bersih dari laporan keuangan perusahaan. Ukuran perusahaan mengacu pada ukuran Ln total aset masing-masing perusahaan. Sedangkan Intensitas Aset dihitung menggunakan capital intensity ratio. Semakin besar nilai rasio, semakin tinggi aset yang dibutuhkan untuk menghasilkan penjualan. Semakin tinggi nilai capital intensity ratio semakin sulit perusahaan untuk menekan biaya ketika pendapatan mengalami penurunan. Capital intensity ratio dihitung dengan rumus sebagai berikut: $\mathrm{CIR}=$ Total Aset $\div$ Penjualan.

Untuk mengukur Modal Intelektual, mengacu pada Ulum (2009) yaitu VAICTM = VACA + VAHU + STAVA. Value Added Intellectual Capital Coefficients VAIC ${ }^{\text {TM }}$ adalah sebuah prosedur analitis yang dirancang untuk memungkinkan manajemen, pemegang saham dan pemangku kepentingan lain yang terkait untuk secara efektif memonitor dan mengevaluasi efisiensi nilai tambah (value added) dengan total sumber daya perusahaan dan masingmasing komponen sumber daya utama. Bontis et al (2000) dalam Ulum (2009) menyatakan bahwa secara umum, para peneliti mengidentifikasi tiga konstruk utama dari intellectual capital, yaitu sebagai berikut:

1. Human Capital (HC) adalah keahlian dan kompetensi yang dimiliki karyawan dalam memproduksi barang dan jasa serta kemampuannya untuk dapat berhubungan baik dengan pelanggan. Termasuk dalam human capital yaitu pendidikan, pengalaman, keterampilan, kreatifitas dan attitude.

2. Structural Capital (SC) adalah infrastruktur yang dimiliki oleh suatu perusahaan dalam memenuhi kebutuhan pasar. Termasuk dalam structural capital yaitu sistem teknologi, sistem operasional perusahaan, paten, merek dagang dan kursus pelatihan.

3. Customer Capital (CC) adalah orang-orang yang berhubungan dengan perusahaan, yang menerima pelayanan dari perusahaan tersebut. Customer capital juga dapat diartikan kemampuan perusahaan untuk mengidentifikasi kebutuhan dan keinginan pasar sehingga menghasilkan hubungan baik dengan pihak luar.

Value added capital employed (VACA) merupakan perbandingan value added (VA) dengan modal fisik yang bekerja (CE). Value Added Human Capital (VAHU) merupakan seberapa besar value added (VA) dibentuk oleh pengeluaran rupiah pekerja. Struktural capital value added (STVA) menunjukkan kontribusi modal struktural (SC) dalam pembentukan nilai. STVA merupakan perbandingan SC dengan VA.

\section{Hasil}

Tabel 2

Uji Normalitas

\begin{tabular}{|l|r|r|}
\hline \multicolumn{2}{|c|}{} & Unstandardized Residual \\
\hline $\mathrm{N}$ & Mean & 192 \\
\hline Normal Parameters & .0342317 \\
\cline { 2 - 3 } & Std. Deviation & .45010391 \\
\hline Most Extreme Differences & Absolute & .062 \\
\cline { 2 - 3 } & Positive & .059 \\
\cline { 2 - 3 } & Negative & -.062 \\
\hline \multicolumn{2}{|l|}{} & .062 \\
\hline Test Statistic & $.070^{\mathrm{c}}$ \\
\hline
\end{tabular}

Sumber: Olahan Data 
Tabel 2 dapat dilihat bahwa asymp. sig. (2-tailed) bernilai 0.070. hal ini menunjukkan bahwa nilai tersebut lebih besar dari taraf nyata $5 \%(0.070>0.05)$ sehingga dapat dinyatakan data penelitian terdistribusi normal.

Tabel. 3

Hasil Uji Multikolinearitas

\begin{tabular}{|l|l|r|r|}
\hline \multicolumn{2}{|l|}{ Model } & \multicolumn{2}{|c|}{ Collinearity Statistics } \\
\cline { 3 - 4 } & Constant & Tolerance & VIF \\
\hline & Penjualan & 1.000 & 1.000 \\
& Ukuran Perusahaan & .856 & 1.211 \\
& Intensitas Aset & .816 & 1.212 \\
& Modal Intelektual & .421 & 1.331 \\
\hline
\end{tabular}

Sumber: Olahan Data

Tabel 3 diatas dapat diketahui bahwa nilai tolerance variabel independen sebesar 1,000 seluruh variabel berada diatas standar tolerance 0,10 sedangkan nilai VIF semua variabel indenpendennya lebih kecil dari 10. Hal ini berarti bahwa hasil analisis menunjukan tidak ada terdapatnya gejala multikoloniearitas sehingga pengujian layak menggunakan model regresi berganda. Tabel 4 diatas dapat diketahui bahwa nilai probabilitas signifikansi seluruh variabel independen sebesar berada diatas tingkat nilai kepercayaan sebesar 5\%. Jadi dapat disimpulkan model regresi ini tidak mengandung adanya gejala heteroskedastisitas. Tabel 5. diperoleh 2.543 Hasil tersebut lebih besar dari nilai DU dimana berdasarkan tabel Durbin -Watson N=32, K=4 sebesar 1.29 dan lebih kecil dari 4 - DU $(4-1.29=2.71)$. Hasil tersebut menunjukkan bahwa DU < DW $<4-$ DU , sehingga dapat disimpulkan bahwa model regresi tidak terjadi autokorelasi. Tabel 6 memiliki nilai F hitung sebesar 9.595 dan F tabel sebesar 2.901 artinya $F$ hitung $>\mathrm{F}$ tabel (9.595 > 2.922) maka H0 di tolak. Jadi dapat disimpulkan bahwa Penjualan, Ukuran Perusahaan, Intensitas Asset, dan Modal Intelektual bersama - sama berpengaruh terhadap Sticky Cost.

Tabel 4

Hasil Uji Heteroskedastisitas

\begin{tabular}{|ll|r|r|r|}
\hline & \multicolumn{1}{c|}{ Model } & \multicolumn{1}{c|}{ S } & \multicolumn{1}{c|}{ Sig. } \\
\hline 1 & (Constant) & 3.694 & .000 \\
& Penjualan & -1.164 & .247 \\
& Ukuran Perusahaan & -1.251 & .214 \\
& Intensitas Aset & -1.408 & .162 \\
& Modal Intelektual & -1.184 & .244 \\
\hline
\end{tabular}

Sumber: Olahan Data

Tabel 5.

Hasil Uji Autokorelasi

\begin{tabular}{|ccr|}
\hline Model & Durbin-Watson & \\
\hline 1 & & 2,543 \\
\hline
\end{tabular}

Sumber: Olahan Data

Tabel 6.

Hasil Uji F

\begin{tabular}{|lcccc|}
\hline & Model & F & Sig. & \\
\hline Regression & & & 9,595 & 0,000 \\
\hline
\end{tabular}

Sumber: Olahan Data

Tabel 7

Koefisien Determinasi

\begin{tabular}{|c|c|c|c|c|}
\hline \multicolumn{1}{|c|}{ Model } & $\mathrm{R}$ & $\mathrm{R}$ Square & Adjusted $\mathrm{R}$ Square & Std. Error of the Estimate \\
\hline 1 & $.522^{\mathrm{a}}$ & .273 & .257 & .2456079 \\
\hline
\end{tabular}

Sumber: Olahan Data

Berdasarkan Tabel 7 di atas tampak bahwa variabel penjualan, ukuran perusahaan, intensitas aset, dan modal intelektual secara bersamaan memiliki nilai $\mathrm{R}^{2}$ sebesar 0,257 yang artinya besarnya sumbangan pengaruh antara variabel penjualan, ukuran perusahaan, intensitas aset, dan modal intelektual terhadap variabel sticky cost sebesar $25,7 \%$. Sedangkan sisa dari hasil tersebut sebesar 74,3\% dipengaruhi oleh variabel lain yang tidak digunakan dalam penelitian ini. 
Tabel 8

Analisis Regresi Berganda

\begin{tabular}{|c|c|c|c|c|c|}
\hline \multirow[b]{2}{*}{ Model } & \multicolumn{2}{|c|}{ Unstandardized Coefficients } & \multirow{2}{*}{$\frac{\text { Standardized Coefficients }}{\text { Beta }}$} & \multirow[b]{2}{*}{$\mathrm{t}$} & \multirow[b]{2}{*}{ Sig. } \\
\hline & $\mathrm{B}$ & Std. Error & & & \\
\hline $1 \quad$ (Constant $)$ & .668 & .424 & & 1.576 & .117 \\
\hline Penjualan & .056 & .024 & .156 & 2.380 & .018 \\
\hline Ukuran Perusahaan & .065 & .026 & .162 & 2.527 & .012 \\
\hline Intensitas Aset & .093 & .034 & .186 & 2.728 & .007 \\
\hline Modal Intelektual & .071 & .009 & .556 & 8.145 & .000 \\
\hline
\end{tabular}

Sumber: Olahan Data

Berdasarkan Tabel 8 di atas dapat disusun persamaan model regresi sebagai berikut:

$\mathrm{Y}=0,668+0,056 \mathrm{Penj}+0,065 \mathrm{UP}+0,093 \mathrm{IA}+0,071 \mathrm{MI}$

Hasil menunjukkan bahwa penjualan berpengaruh sticky cost. Dengan demikian hipotesis pertama (H1) yang menyatakan adanya pengaruh antara variabel penjualan terhadap variabel sticky cost didukung. Ukuran perusahaan memiliki nilai signifikansi (sig.) sebesar 0,012 yang artinya ada pengaruh antara ukuran perusahaan terhadap variabel sticky cost. Hasil tersebut $<0,05$ yang membuktikan hipotesis kedua $(\mathrm{H} 2)$ yang menyatakan adanya pengaruh antara variabel ukuran perusahaan terhadap variabel sticky cost didukung. Intensitas aset memiliki nilai signifikansi (sig.) sebesar 0,007 yang artinya ada pengaruh antara variabel intensitas aset terhadap variabel sticky cost. Hasil ini menunjukkan bahwa hipotesis ketiga (H3) yang menyatakan adanya pengaruh antara variabel intensitas aset terhadap variabel sticky cost diterima. Modal intelektual (X4) memiliki nilai signifikansi (sig.) sebesar 0,000 yang artinya ada pengaruh antara variabel modal intelektual terhadap variabel sticky cost. Hasil tersebut $<0,05$ yang menunjukkan hipotesis keempat (H4) yang menyatakan adanya pengaruh antara variabel modal intelektual terhadap variabel sticky cost diterima.

\section{Simpulan}

Berdasarkan hasil diperoleh bahwa penjualan berpengaruh terhadap sticky cost. Demikian pula ukuran perusahaan berpengaruh terhadap sticky cost. Intesitas aset berpengaruh terhadap sticky cost, ini menunjukkan semakin tinggi aset yang ada ketika volume penjualan mengalami peningkatan maka mudah saja bagi perusahaan untuk memproduksi barang dalam jumlah yang besar. Modal intelektual terbukti berpengaruh terhadap sticky cost. Secara simultan, penjualan, ukuran perusahaan, intensitas aset, modal intelektual berpengaruh terhadap sticky cost. Penelitian ini hanya dilakukan pada perusahaan sektor industri barang konsumsi yang terdaftar di Bursa Efek Indonesia tahun 2012-2017 sehingga kehati-hatian diperlukan dalam melakukan interpretasi. Untuk melakukan eksplorasi mengenai hal yang mempengaruhi sticky cost, riset kualitatif dapat dilaksakanan dengan melakukan observasi langsung pada perusahaan untuk mengembangkan dan mengekplorasi factor yang mempengaruhinya (Azmi et al, 2019).

\section{Daftar Pustaka}

Anderson, M., Banker, R.D., dan Janakiraman, S.N. (2003). Are Selling, General, And Administrative Costs Sticky?. Journal Of Accounting Research, 41(1): 47-63.

Afiffah, A., Murdayanti, Y., dan Purwohedi, U. (2018). Fenomena Perilaku Sticky Cost Pada Perusahaan Manufaktur Di Indonesia. Jurnal Akuntansi, Vol. 18 No. 1a, Januari-Juni 2018: 141-152.

Aprayuda, R., \& Misra, F. (2020). Faktor-faktor yang mempengaruhi keinginan investasi investor muda di pasar modal Indonesia. E-Jurnal Akuntansi Universitas Udayana, 30(5), 1084-1098. https://doi.org/10.24843/eja.2020.v30.i05.p02

Aprayuda, R., Misra, F., \& Kartika, R. (2021). Does Order of Information Affect Investors' Investment Decisions?: Experimental Investigation. Journal of Accounting and Investment, 22(1), 150-172.

Azmi, Z., Nasution, A.A., Wardayani, W., Muda, I., Supriyanto, S., Rizal, S., \& Hidayat, R., (2019). Grounded Theory in Accounting Research, Proceeding of the $2^{\text {nd }}$ International Conference on Advance and Scientific Innovation.

Hery, (2017). Kajian Riset Akuntansi. Jakarta: Grasindo.

Husni, T., Rahim, R., \& Aprayuda, R. (2020, April). Cash Compensation, Corporate Governance, Ownership, and Dividend Policy on Banking Performance. In 6th Annual International Conference on Management Research (AICMaR 2019) (pp. 212-218). Atlantis Press.

Mohammadi, A., dan Taherkhani, P. Mei (2017). Organizational Capital, Intellectual Capital And Cost Stickiness. Journal Of Intellectual Capital, 18(3): 625-642. 
Nelmida, dan Siregar, S.O.H. April (2016). Pengaruh Perubahan Penjualan, Capital Intensity Ratio, Debt To Asset Ratio, Dan Current Ratio Terhadap Cost Stickiness Dalam Perusahaan Di Bursa Efek Indonesia. Jurnal Ekonomi, Manajemen Dan Perbankan. Vol. 2 No. 1: 1-10.

Nugroho, P.I., dan Endarwati, W. (2013). Do The Cost Stickiness In The Selling, General And Administrative Costs Occur In Manufacturing Companies In Indonesia?. Simposium Nasional Akuntansi 16 Manado, Sesi III/1: 2705-2718.

Putri, Y. D., Kartika, R., \& Aprayuda, R. (2020). Apakah Dana Zakat Dapat Mengurangi Tingkat Kemiskinan?: Studi Kasus Provinsi Sumatra Barat. Jurnal Tabarru': Islamic Banking and Finance, 3(2), 248-261.

Putra, D. G., Syofyan, R., \& Aprayuda, R. (2020). Influence Of Company Value Information, Dividend Policy, And Capital Structure On Stock Price. SAR (Soedirman Accounting Review): Journal of Accounting and Business, 5(2), 152-169.

Pamplona, E., Fiirst, C., Jesus Silva, T.B., dan Zonatto, V.C.D.S. (2016). Sticky Cost In Cost Behavior Of The Largest Companies In Bazil, Chile And Mexico. Contaduría Y Administración, 61 (2016): 682-704.

Ramashar, W., Anriva, D.H., Azmi, Z., \& Binangkit, I.D., (2019), the effect of intellectual capital and company size on sticky cost, Jurnal akuntansi dan ekonomika, Vol. 9 no.2, 233-242

Subramanyam, K.R., dan Wild, J.J., (2016). Analisa Laporan Keuangan. Jakarta: Salemba Empat.

Sofyan, R., Putra, D. G., \& Aprayuda, R. (2020, November). Does the Information on the Internet Media Respond to the Stock Market?. In The Fifth Padang International Conference On Economics Education, Economics, Business and Management, Accounting and Entrepreneurship (PICEEBA-5 2020) (pp. 510-520). Atlantis Press.

Ulum, I. (2009). Intellectual Capital; Konsep Dan Kajian Empiris, Yogyakarta: Graha Ilmu.

Venieris, G., Naoum, V.C., dan Vlismas, O. (2015). Organisation Capital And Sticky Behaviour Of Selling, General And Administrative Expenses. Journal Of Management Accounting Research, 26: 54-82.

Wahyuningtyas, Y., dan Nugrahanti, Y.W. (2014). Pengaruh Asset Intensity Dan Employee Intensity Terhadap Sticky Cost Pada Biaya Penjualan, Administrasi Dan Umum. Jurnal Ekonomi Dan Bisnis. Vol. 8 No. 2: 113-121.

Windyastuti. (2013). Penetapan Target Terhadap Stickiness Cost. Jurnal Keuangan Dan Perbankan, Vol. 17 No. 1 Januari 2013: 71-77. 